\title{
ACHIEVING THE DESIRED TRANSFORMER LEAKAGE INDUCTANCE NECESSARY IN DC-DC CONVERTERS FOR ENERGY STORAGE APPLICATIONS
}

\author{
D. De, C. Klumpner, M. Rashed, C. Patel, P. Kulsangcharoen, G. Asher \\ Department of Electrical and Electronics Engineering \\ University of Nottingham, NG7 2RD, UK \\ Email: dipankar.de@nottingham.ac.uk
}

Keywords: Leakage inductance Medium frequency transformer, Winding arrangements, Winding losses.

\begin{abstract}
This paper presents a cost effective winding design and evaluation of a medium frequency isolation transformer typically used in bidirectional isolated DC/DC converters. Since leakage inductance and winding resistance of a high frequency transformer are interdependent, any attempt to increase the leakage inductance by adjusting the winding arrangement increases the resistance as well and impacts the efficiency. This paper proposes the use of flux diverter caps made of a relatively small amount of ferrite material to get the desired value of inductance whilst maintaining the losses in the windings at reasonable levels. The proposal is experimentally evaluated on a $5 \mathrm{~kW}$ prototype.
\end{abstract}

\section{Introduction}

In a typical energy storage system, low voltage energy storage cells need to be interfaced with a medium voltage ac grid. A cascaded multilevel inverter supplied from isolated/floating energy storage cells may be seen as one of the simplest alternatives [1]-[5], but the implementation issues related to isolation are actually transferred from the power electronics to the energy storage devices; hence price reduction is not straightforward. An alternative solution is to supply the multilevel converter from a single energy storage unit via a set of bidirectional DC/DC converters that use medium frequency power transformer [6]-[8] (Fig. 1). The energy storage system may consist of batteries and/or super capacitors and connect to a common low voltage DC bus via individual buck-boost converters. The bidirectional isolated DC-DC converter which is the topic of this paper is shown in Fig. 2 [9], [10] and it may typically require a given leakage/separate inductance in order to provide proper control of the currents. Adding a separate inductor in series with the transformer to achieve the desired value of the inductance increases overall size, cost and losses of the system. A more elegant alternative is to modify the transformer design to integrate the desired leakage inductance [11]. The design of the medium frequency transformer with a specific value of leakage inductance for a $\mathrm{DC} / \mathrm{DC}$ converter is crucial for optimizing the overall cost (no extra inductance required) and operating efficiency of the system and to achieve a reasonable controllability of the power flow.

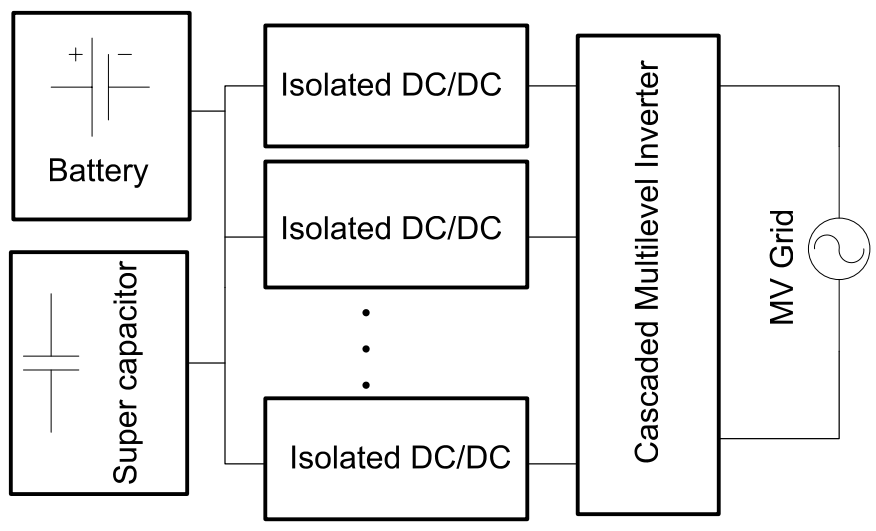

Figure 1: Energy storage system interfaced with grid.

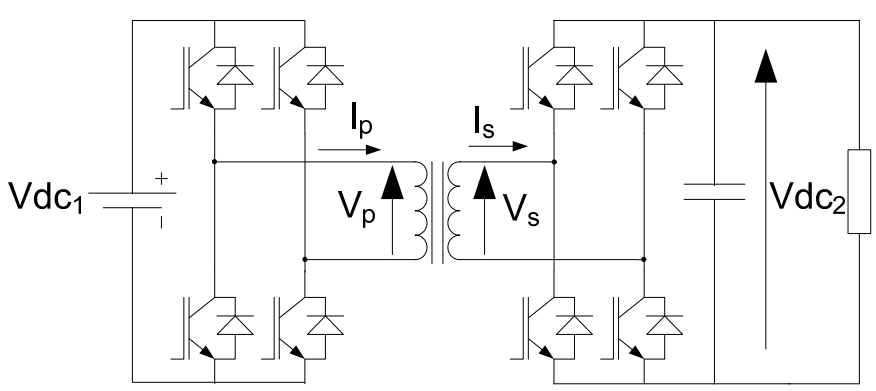

Figure 2: Bidirectional isolated DC-DC converter [10].

This paper focuses on the winding design, its arrangement and evaluation of a medium frequency transformer to achieve a desired value of the leakage inductance. However, as any increase in leakage inductance results in an increase of the winding resistance; it implies that there may be a trade off between added leakages vs. winding losses that has to be dealt with. In [12], a leakage layer was included in the transformer construction to improve the leakage inductance. However in certain situations, inclusion of a leakage layer leads to more losses in the foil winding due to the existence of radial component of the leakage field [13] and hence requires 
more expensive winding material (use of litz wire). The proposal is to use a magnetic flux diverter to improve the performance. The trade-off between the efficiency of the transformer (resistance), the value of added leakage inductance and the other implementation aspects is evaluated.

\section{System description}

The design specifications for the transformer are given in Table.1 where Vp: primary voltage, Vs: secondary voltage, Po: output power, f: frequency of operation of the transformer. The particular value of leakage inductance is important as a smaller value of the inductance causes instability in the control at low current whilst a large inductance limits the power transfer capability. In order to achieve this specification, various transformer constructions have been investigated and implemented. In Fig. 3, three evaluated transformers with different winding configurations using copper foil are shown.

\begin{tabular}{|c|c|}
\hline Vp [rms] & $325 \mathrm{~V}$ \\
\hline Vs [rms] & $325 \mathrm{~V}$ \\
\hline Po [W] & $5 \mathrm{~kW}$ \\
\hline $\mathrm{f}[\mathrm{Hz}]$ & $6 \mathrm{kHz}$ \\
\hline Desired Leakage Inductance & $200-250 \mu \mathrm{H}$ \\
\hline
\end{tabular}

Table 1: Transformer specifications

Here the copper foil is preferred compared to the Litz wire from the point of view of cost. In Fig. 3(a), a conventional structure of the transformer is shown where the full number of primary turns is wound on the top of the full secondary winding. Although this construction is simple and efficient (low winding resistance, $0.13 \Omega$ ), it does not provide sufficient leakage inductance (only $113 \mu \mathrm{H}$ ). In order to achieve the total desired inductance, an additional $120 \mu \mathrm{H}$ inductor is necessary accounting for an additional $25 \%$ of the physical size of the transformer and also extra circuit resistance. The transformer construction was then modified as illustrated in Fig. 3(b) where the windings are separated into two sections and each section is wound on a different limb of the core. This arrangement increased the leakage inductance up to $132 \mu \mathrm{H}$ $(\mathrm{N} 1=\mathrm{N} 2)$. By creating an unbalance in the number of turns of the primary and the secondary per coil, it is possible to increase the MMF applied to the possible leakage flux paths and hence to increase the leakage inductance of the transformer $(176 \mu \mathrm{H})$. However, since the design results in a too large mean turn length, the design was modified to reduce the overall length of the windings by splitting the winding into 4 sections as shown in Fig. 3(c).

A secondary effect of increasing the unbalance between the primary and the secondary number of turns in each coil (and hence the leakage flux) is that the resistance of the winding also increases along with the inductance. This finding was experimentally determined for different asymmetry levels and is shown in Fig. 5(a) and 5(b) (dotted line) for the configuration shown in Fig. 3(c). These results are obtained from the measurements carried out by a digital RLC meter, PSM1735 where the winding unbalance is defined as:

$$
\text { W_unb }=0.5(\mathrm{~N} 1-\mathrm{N} 2)
$$

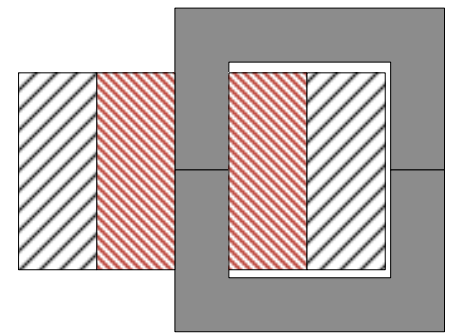

(a) Balanced winding arrangement

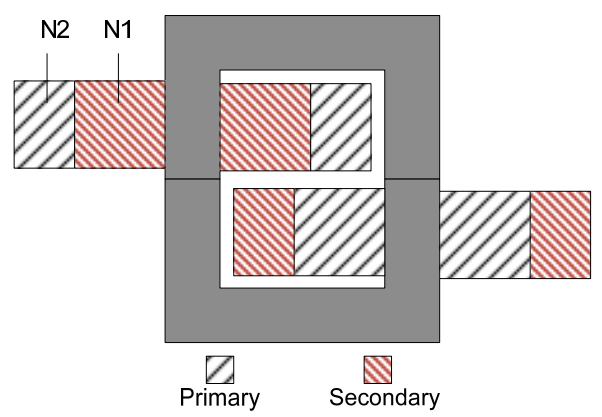

(b) Unbalanced case - two sections (or coils)

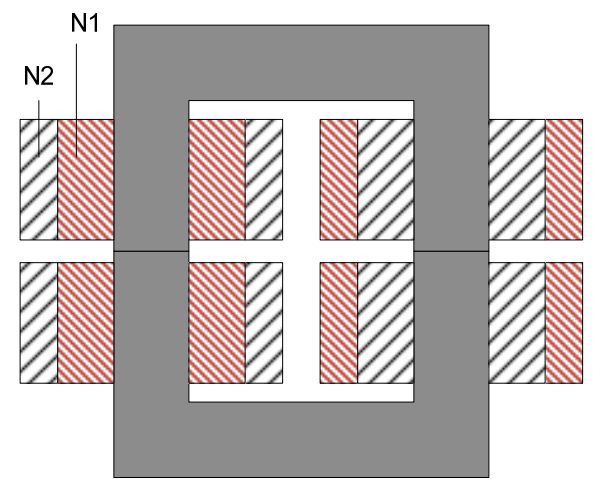

(c) 4 coil transformer with unbalanced winding

Figure 3: Different winding arrangements of medium frequency transformer that were evaluated

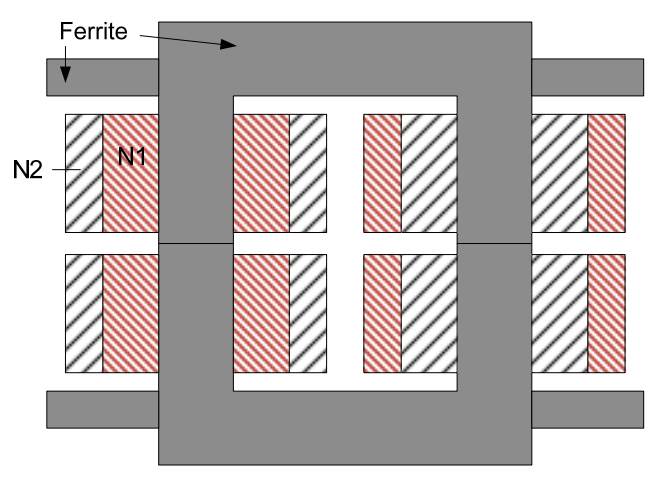

Figure 4: Proposed structure of the transformer 


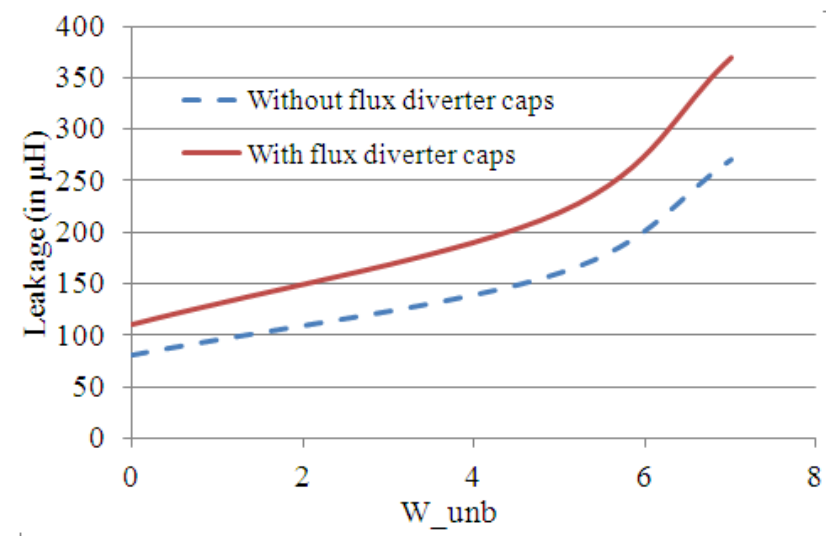

(a) Variation of leakage inductance

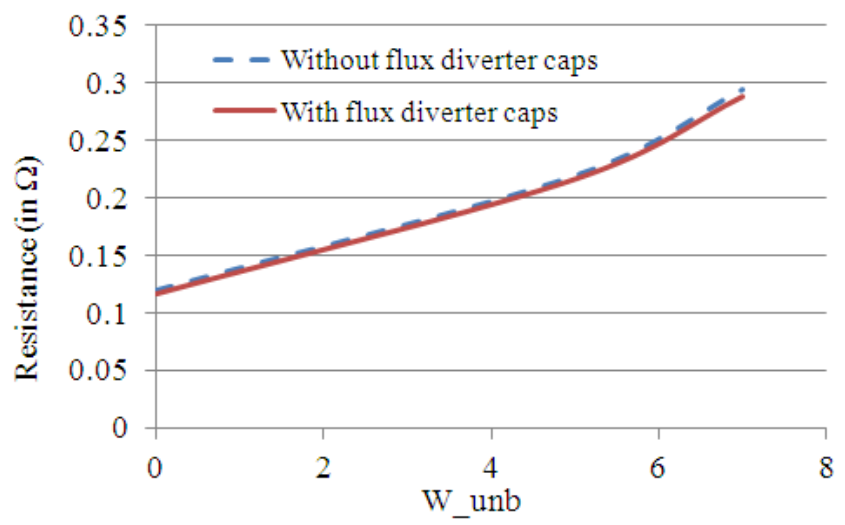

(b) Variation of winding resistance at $6 \mathrm{kHz}$

Figure 5: Comparison of the measured parameters

The increase in the resistance is due to the increase in the leakage flux that cut the foil windings and hence creates more losses in the foil by the eddy currents. In this paper a modified structure with unbalanced number of turns per coil is proposed to increase the leakage inductance to the desired value while maintaining nearly same winding resistance.

The proposed configuration of the transformer is shown in Fig. 4. It consists of an additional inexpensive flux diverter made out of ferrite rods placed in the same plane as the end caps of the coils (Fig. 4). The inductance and resistance of the transformer winding with ferrite tops and different unbalance winding factor are shown in Fig. 5(a) and 5(b) (solid line). The reason behind this improvement is confirmed using a finite element tool from Infolytica Corporation (Fig. 6(a) and 6(b)). The added magnetic component decreases the reluctance of the leakage flux path and hence it helps to increase the leakage flux (i.e. inductance). In addition, the leakage flux lines (strong in magnitude) intersect the foil with slightly smaller angle (leakage flux lines become "more parallel" to the copper foil in Fig. 6(b) in comparison to the case in Fig. 6(a)), which yields to nearly the same high frequency losses for a higher value of leakage flux and hence the winding resistance remains nearly the same. The leakage inductance obtained from the FEM simulations in Fig. 6(a) and Fig. 6(b) are $45 \mu \mathrm{H}$ and $61 \mu \mathrm{H}$ respectively. These values indicate the increase of the leakage inductance of the transformer with ferrite rods. However, these values do not match with the measured values as the 2-D model accounts for only/less than $1 / 3$ of the surface of the flux diverter as it can be seen in Fig. 7. The photograph of the transformer is shown in Fig. 8.

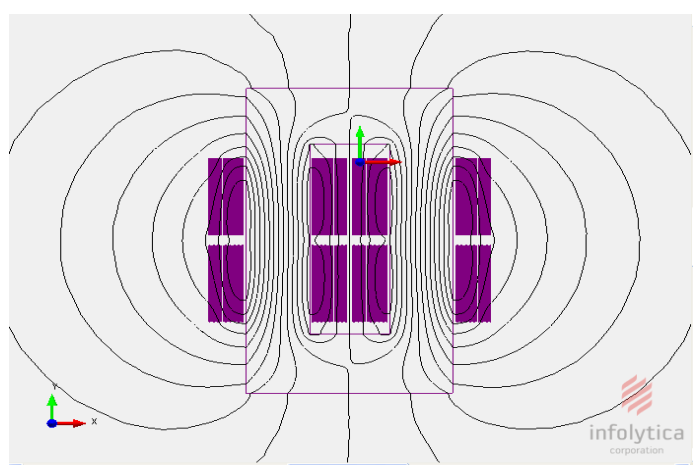

(a) Flux lines for transformer in Fig. 3(c)

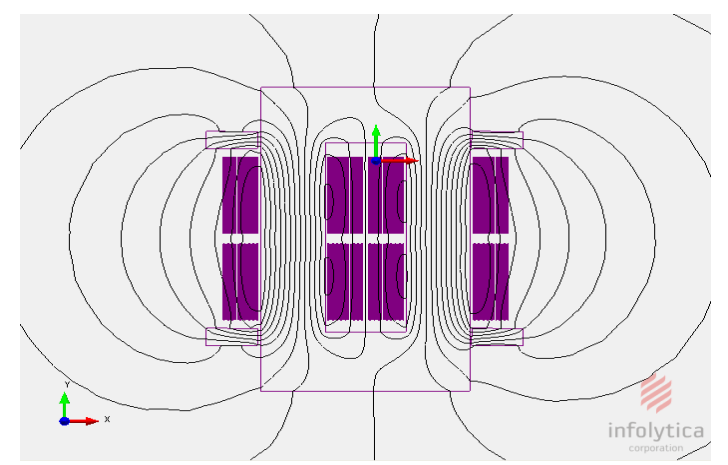

(b) Flux lines for transformer in Fig. 4

Figure 6: Comparison of the path of the leakage flux lines as determined using a 2D FEM tool by Infolytica

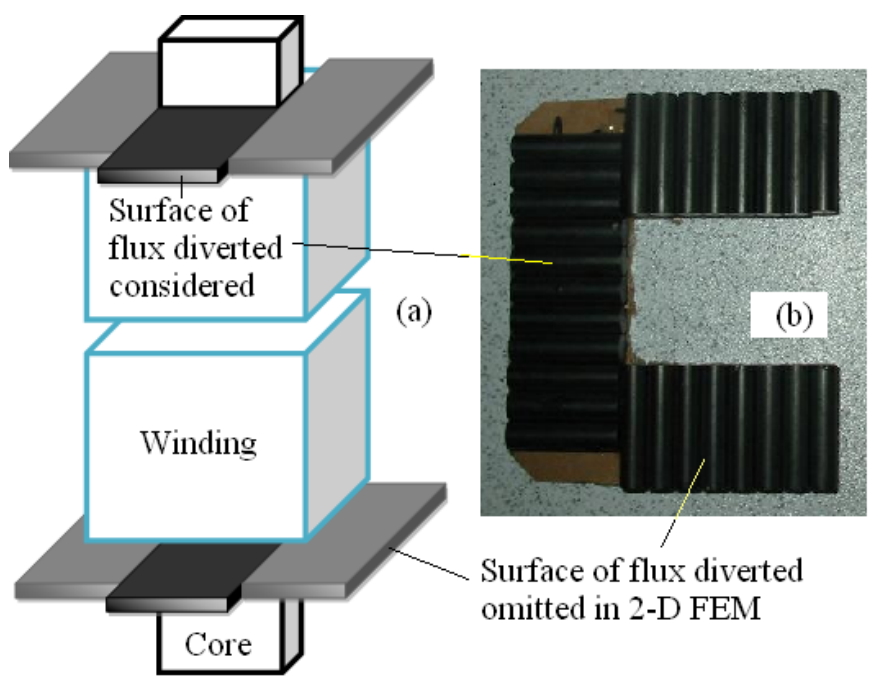

Figure 7: Justification of the inconsistency between measured and 2D FEM simulation: (a) winding a flux diverter arrangements highlighting the part considered in the 2D FEM and the ones not considered; (b) physical implementation of one of the flux diverter caps 


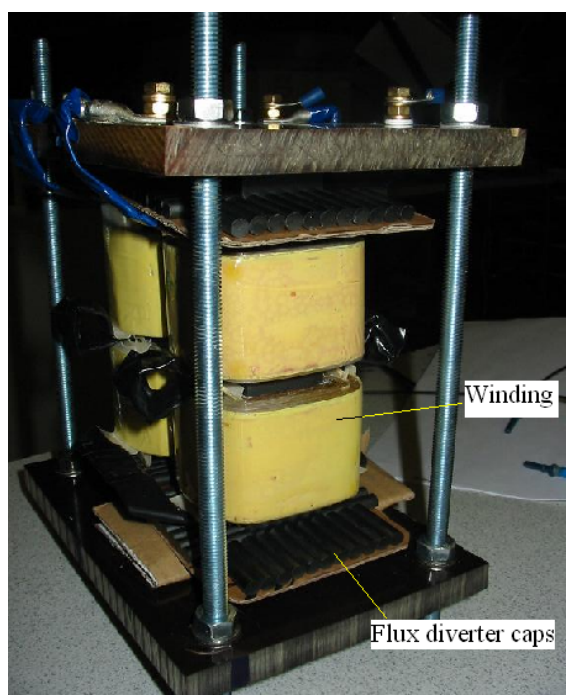

Figure 8: Photograph of the transformer with flux diverter cap

\section{Experimental Results}

The designed transformer (details are given in Table. 2) is experimentally tested in a dual active bridge inverter configuration shown in Fig. 9. The transformer is connected between two H-Bridges (HBs) fed back to back from a common DC source. A Digital signal processor based controller commands in open loop the current reference to circulate power between the two $\mathrm{HBs}$ in order to directly measure the system losses. In this arrangement only losses are supplied from the DC source. A three channel power analyzer, NL4PA2530 is connected in the power circuit to measure the power in and out (and therefore the losses) of one of the HB and the transformer. Phase 1 (P1), phase 2 (P2), and phase $3(\mathrm{P} 3)$ of the power analyzer are connected as shown in Fig. 9.

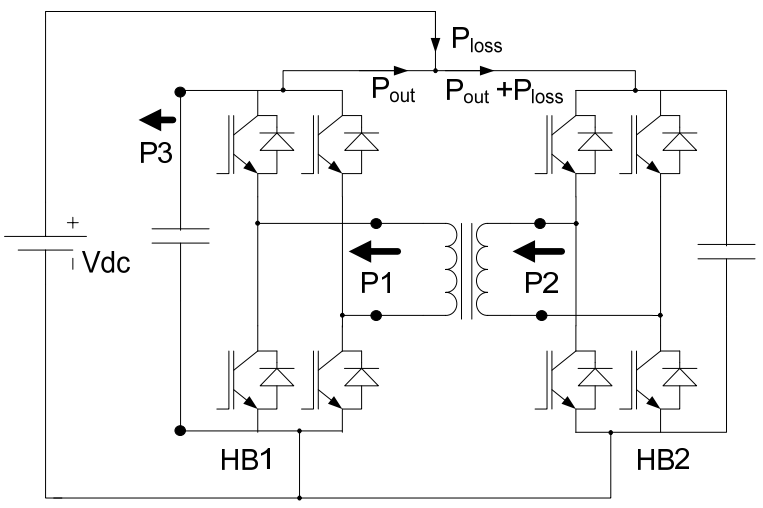

Figure 9: Block Diagram of the experimental setup

The measured waveforms (Vp, Vs, Ip, and Po) at full load are shown in Fig. 10 with square wave excitation. Fig. 11 and Fig. 12(a) show the measured current waveforms of the transformer with and without the ferrite rods and the corresponding harmonics spectrum. It can be observed that the current waveform is more flat and with lower harmonics when using the flux diverter caps (i.e. increased leakage inductance case). More flatten transformer current proves that more leakage inductance is present in the second case without further increasing the unbalance in the winding arrangement (and hence keeping same transformer copper losses). Fig. 12(b) and Fig. 12(c) show the variation of winding resistance and corresponding losses caused by the current harmonics present due to trapezoidal current shape. The total winding losses are decreased from $66.5 \mathrm{~W}$ to $61.7 \mathrm{~W}$ with the inclusion of the flux diverter caps.

\begin{tabular}{|c|c|}
\hline Core & U93/152/30 (EPCOS) \\
\hline $\mathrm{Cu}$ Foil thickness & $0.157 \mathrm{~mm}$ \\
\hline $\mathrm{Cu}$ foil width & $38 \mathrm{~mm}$ \\
\hline Number of primary turns & 42 \\
\hline Turns ratio & $1: 1$ \\
\hline Unbalance in winding & 5 \\
\hline Leakage Inductance & $220 \mu \mathrm{H}$ \\
\hline
\end{tabular}

Table 2: Parameters of final $5 \mathrm{~kW}$ Transformer prototype

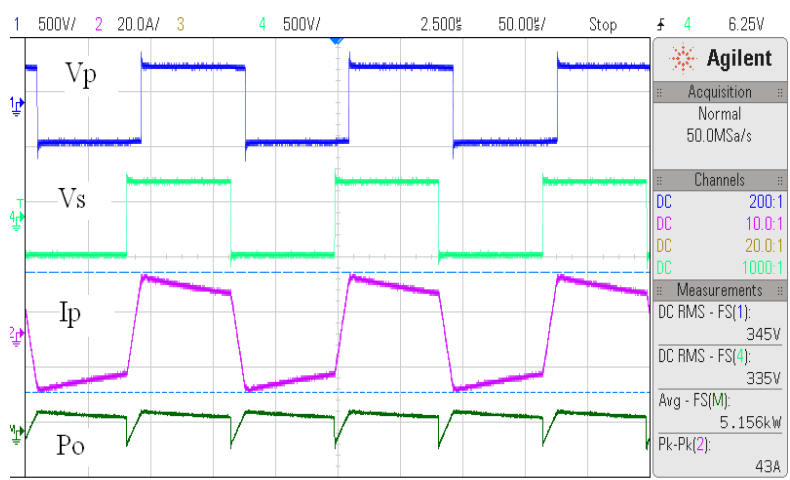

Figure 10: Measured results from the transformer

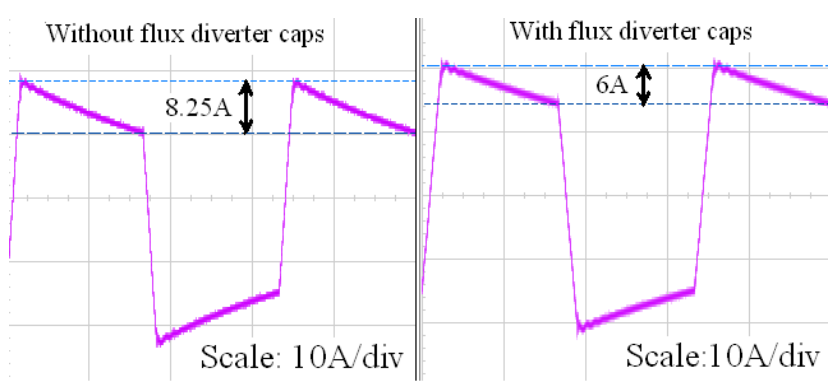

Figure 11: Comparison of primary current in both conditions with same RMS value

The power flow measurements performed using the precision power analyzer is shown in Fig. 13, without and with the flux diverter caps. The power flow direction is $\mathrm{P} 2 \rightarrow \mathrm{P} 1 \rightarrow \mathrm{P} 3$. In the first case, the input power to the transformer is $5.2394 \mathrm{~kW}$ and output from the transformer and converter are $5.1615 \mathrm{~kW}$ and $5.0737 \mathrm{~kW}$ respectively (Fig. 13(a)). The efficiency of the transformer and the HB without flux diverter caps are $98.46 \%$ and $98.26 \%$ respectively. When using the flux diverter caps, the efficiencies change to $98.60 \%$ and $98.19 \%$ respectively. It 
can be observed that the overall losses remain nearly same; however, there is a small shift in losses between the transformer and the HB inverter. Table. 3 shows the core loss components with various harmonics order. The table shows that above $3^{\text {rd }}$ order, the effect of voltage harmonics on the core loss is negligible.

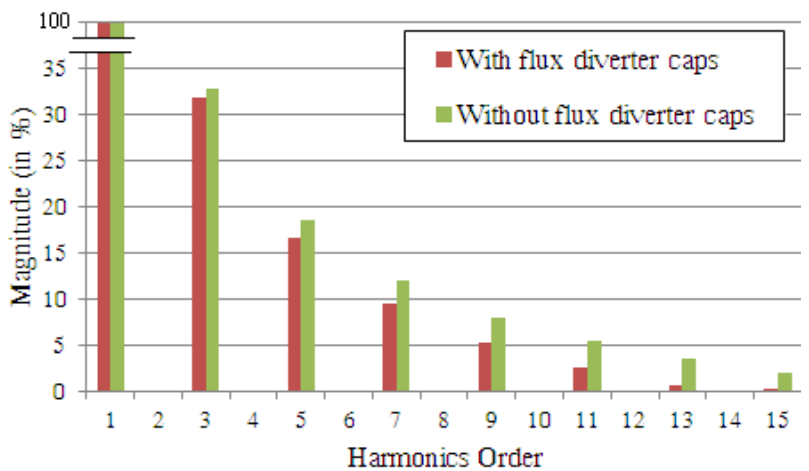

(a) Harmonic content in Fig. 11

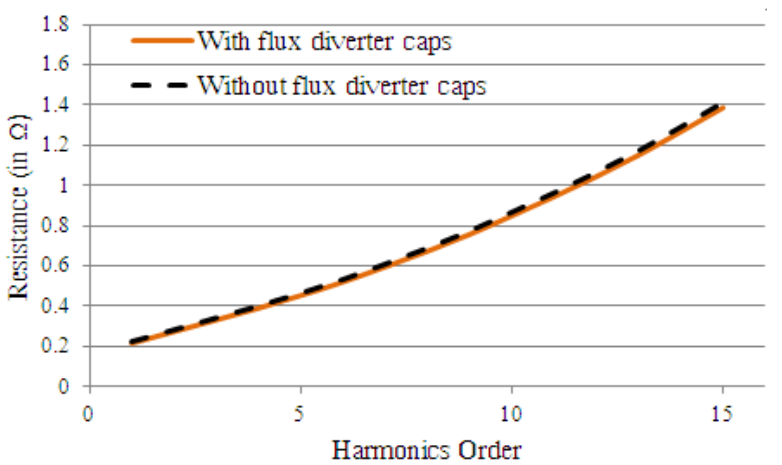

(b) Winding resistance variation with frequency

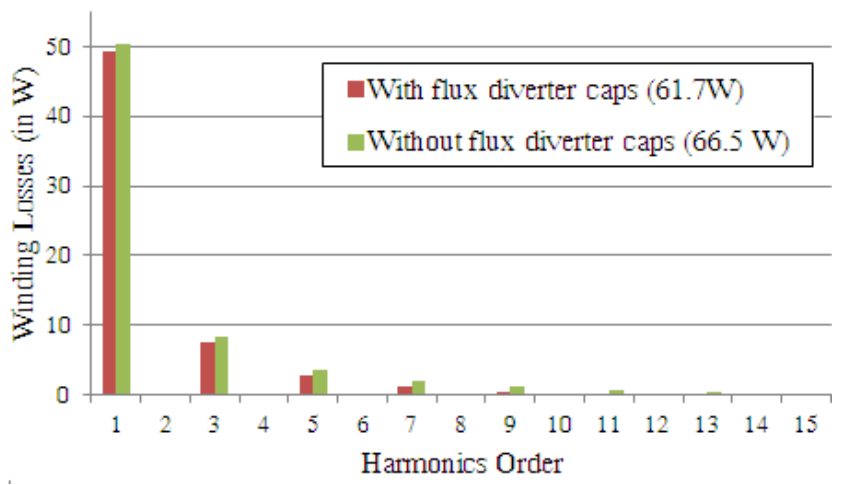

(c) Winging losses

Figure 12: Measured results and comparison

\begin{tabular}{|c|c|c|}
\hline $\begin{array}{c}\text { Harmonics } \\
\text { Order }\end{array}$ & $\begin{array}{c}\text { Peak applied } \\
\text { Voltage (V) }\end{array}$ & $\begin{array}{c}\text { Core Losses } \\
(\mathrm{W})\end{array}$ \\
\hline 1 & 413.75 & 9.207 \\
\hline 3 & 137.78 & 0.927 \\
\hline 5 & 82.50 & 0.118 \\
\hline 7 & 58.75 & 0.023 \\
\hline \multicolumn{2}{|c}{ Total Core losses } \\
\hline
\end{tabular}

Table. 3: Core loss in the power transformer

\begin{tabular}{|lllll|}
\hline \multicolumn{5}{c|}{ POWER ANALYZER } \\
Watts & phase 1 & phase 2 & phase 3 & \\
VA & $-5.1615 \mathrm{k}$ & $5.2394 \mathrm{k}$ & $-5.0737 \mathrm{k}$ & W \\
VAr & $5.8242 \mathrm{k}$ & $5.6048 \mathrm{k}$ & $5.0763 \mathrm{k}$ & VA \\
pf & $2.6983 \mathrm{k}$ & $1.9906 \mathrm{k}$ & 162.83 & VAr \\
Vrms & $886.21 \mathrm{~m}$ & $934.80 \mathrm{~m}$ & $999.49 \mathrm{~m}$ & \\
Arms & 343.22 & 331.84 & 341.26 & V \\
frequency & 16.969 & 16.890 & 14.875 & V \\
H3 & $6.0000 \mathrm{kHz}$ & & & \\
dc watts & 9.3945 & 9.5517 & 6.3478 & $\%$ \\
V ph-ph & $8.2038 \mathrm{~m}$ & $4.4433 \mathrm{~m}$ & $-5.0715 \mathrm{k}$ & W \\
& 226.33 & 464.38 & 484.02 & W \\
& & & & \\
\hline
\end{tabular}

(a) Without the flux diverter caps

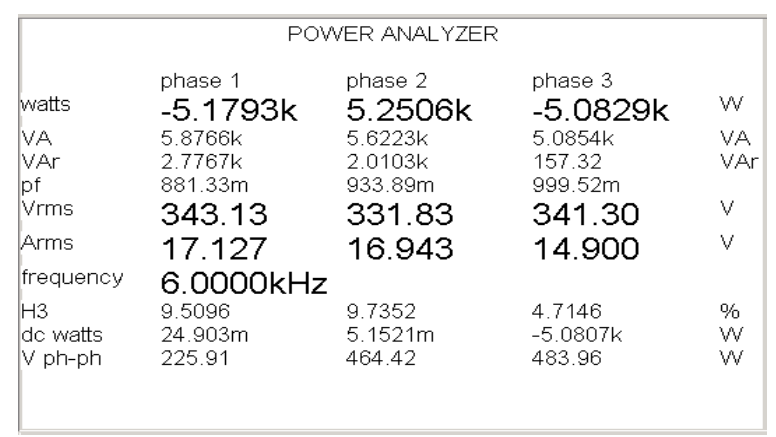

(b) With the flux diverter caps

Figure 13: Measured result from the power analyzer

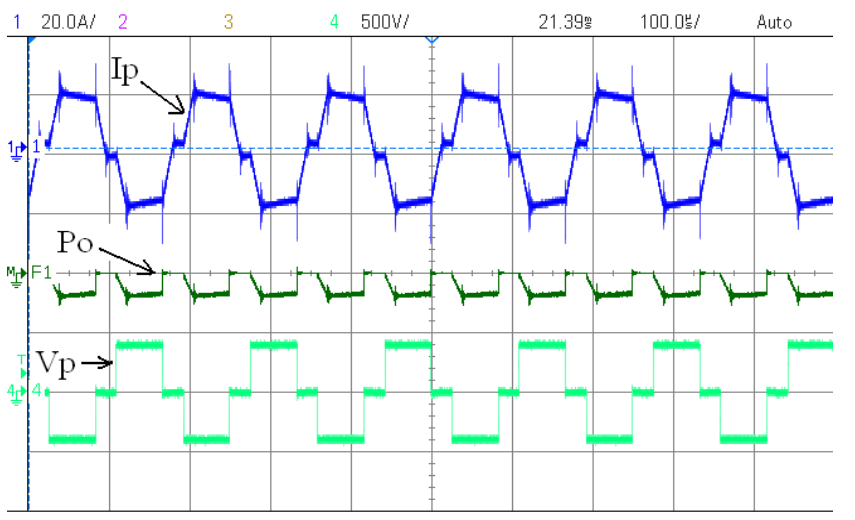

Figure 14: Operation with quasi-square wave excitation (Ip: 20A/div, Po: $10 \mathrm{~kW} / \mathrm{div}, \mathrm{Vp}: 500 \mathrm{~V} / \mathrm{div}$, time: $100 \mu \mathrm{sec} / \mathrm{div}$ )

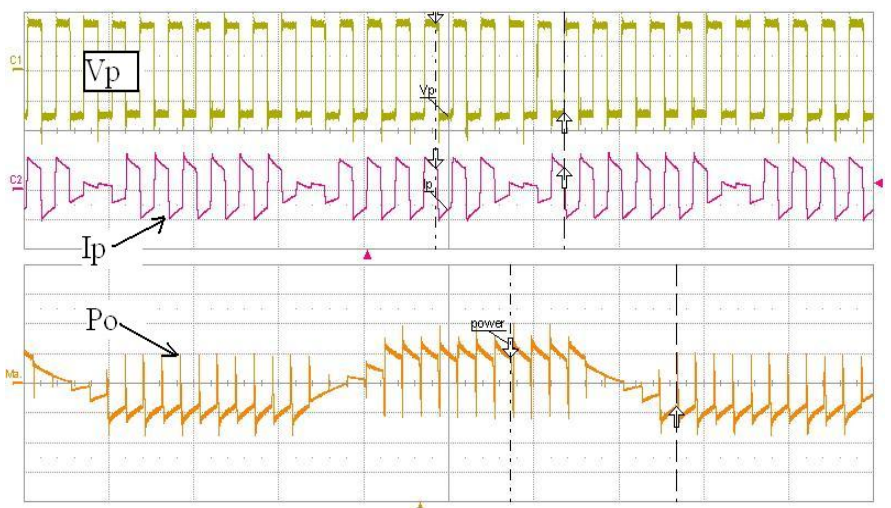

Figure 15: Power reversal: Vp (200V/div), Ip (20A/div), Po $(5 \mathrm{~kW} / \mathrm{div})$, time: $500 \mu \mathrm{sec} / \mathrm{div}$ 
The experimental results with the quasi-square waveform and a fast power reversal, which is an essential attribute for energy storage applications, are shown in Fig. 14 and Fig. 15 respectively. The measured efficiency of the transformer and the full system at various loading condition $(10 \%$ to $100 \%)$ are plotted in Fig. 16(a) and 16(b) respectively. It can be observed that with quasi square wave excitation, the overall efficiency is slightly smaller compared to square wave excitation at full load, however, at reduced load (10\%) where core losses become predominant, quasi square wave becomes marginally more efficient. The overall fairly flat efficiency curve that peaks at reduced power levels may be important for an energy storage system to achieve high overall efficiency over a cycle/roundtrip where it is highly possible that most of the time, the system will operate at below rated conditions.

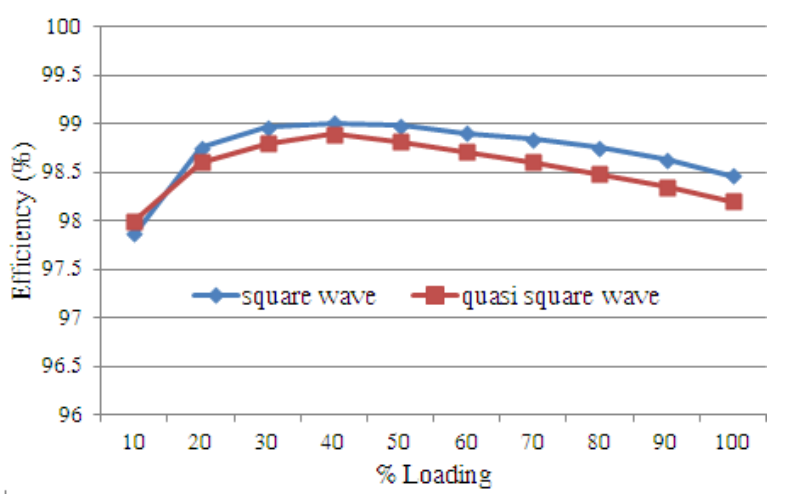

(a) Transformer

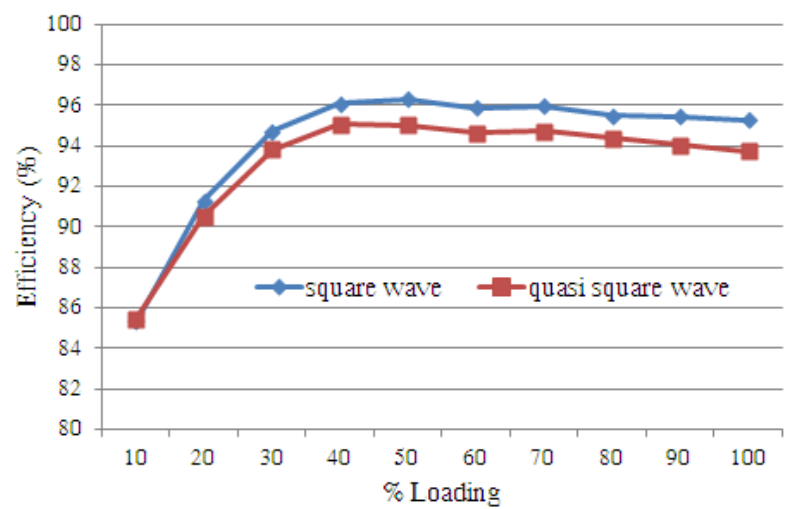

(b) Complete system

Figure 16: Measured efficiency of the transformer and complete system at various loading with flux diverter caps

\section{Conclusion}

The winding design and the experimental evaluation of a high frequency transformer to be used in a DC/DC converter with isolation are presented in this paper. The effects of asymmetric winding arrangements on the leakage inductance and winding resistance are studied. It has been observed that there is positive dependency between resistance and inductance of the isolation transformer. An insertion of a flux diverter cap made of inexpensive ferrite rods on either side of the winding increases the inductance without affecting the value of the winding resistance. A full experimental evaluation of the DC/DC converter that includes power loss measurement shows that each H-bridge and transformer operate with more than $98 \%$ efficiency at full load with square wave excitation.

\section{Acknowledgements}

The project this report is based on was funded by E.ON as a part of E.ON International Research Initiative. Responsibility of the content of this publication lies with the author.

\section{References}

[1] L. M. Tolbert, F. Z. Peng. "Multilevel converters as a utility interface for renewable energy systems", IEEE PESS, volume 2, pp. 1271-1274, (2000).

[2] H. Akagi, L. Maharjan. "A battery energy storage system based on a multilevel cascaded PWM converter", IEEE COBEP, pp. 9-18, (2009).

[3] M. E. Ortuzar, R. E. Carmi, J. W. Dixon, L. Moran. "Voltage source active power filter based on multilevel converter and ultra-capacitor DC link", IEEE Trans. Ind. Electron., volume 53, no. 2, pp. 477-485, (2006).

[4] J. Vassallo, J. C. Clare, P. W. Wheeler. "A multilevel power conversion scheme for non-isolated DC sources", IEEE PESC, volume 5, pp. 3534-3540, (2004).

[5] L. Maharjan, S. Inoue, H. Akagi. "A transformer-less energy storage system based on a cascaded multilevel PWM converter with star configuration", IEEE Trans. Ind. Applicat., volume 44, no. 5, pp. 1621-1630, (2008).

[6] T. Zhao, G. Wang, J. Zeng, S. Dutta, S. Bhattacharya, A. Q. Huang. "Voltage and power balance control for a cascaded multilevel solid state transformer", IEEE APEC, pp. 761-767, (2010).

[7] J. Shi, W. Gou, H. Yuan, T. Zhao, A. Q. Huang. "Research on voltage and power balance control for cascaded modular solid state transformer", IEEE Trans. Power Electron., volume 26, no. 4, pp. 1154-1166, (2011).

[8] M. Rashed, C. Klumpner, G. Asher. "High performance multilevel converter topology for interfacing energy storage systems with medium voltage grid", IEEE INCON, pp. 18251831, (2010).

[9] M. H. Kheraluwala, D. W. Novotny, D. M. Divan. "Coaxially wound transformers for high power high frequency applications", IEEE Trans. Power Electron., volume 7, no. 1, pp. 54-62, (1992).

[10] R. Doncker, D. M. Divan. "A three phase soft switched high power density dc/dc converter for high power application", IEEE Trans. Ind. Applicat., volume 27, no. 1, pp. 63-73, (1991).

[11] Y. D. Kim, C. E. Kim, K. M. Cho, K. B. Park, G. W. Moon. "ZVS phase shift full bridge converter with controlled leakage inductance of transformer", IEEE INTLEC, pp. 1-5, (2009).

[12] M. Pavlovsky, S.W.H. de Hann, J. A. Ferreira. "Winding losses in high current high frequency transformer foil winding with leakage layer", IEEE PESC, pp. 1-7, (2006).

[13] P. D. Kvans, K. H. Al-shara. "Losses in foil wound secondary in high frequency transformers", IEEE Trans. Magnetics, volume 25, no. 4, pp. 3125-3132, (1989). 